\title{
The Use of E-Health Information and Health Behavior Change: The Role of Perceived Health Status and Types of E-Health Information Use
}

\author{
Jae Woong Shim*
}

School of Communication, Sookmyung Women's University, Seoul, Korea

\begin{abstract}
This study assessed the relationship between the amount of e-health information use and changes in health behavior, with an emphasis placed on self-perceived health status and different types of e-health information use (purposeful, wary, and listserv). The results of the study indicated that people with low perceived health status were more likely to spend time online searching for health information. Additionally, the findings indicated that changes in health behavior as a result of e-health information use were most likely to occur in people with lower perceived health status in the purposeful e-health type. The implications of these findings for future research are also discussed herein.
\end{abstract}

Keywords: E-health, health behavior, e-health type, perceived health status.

\section{INTRODUCTION}

The Internet has unquestionably changed the flow of health information. Due to the important role of the Internet as an important source of health information, people can now make themselves well-informed and self-involved in health decision-making, based on simple Web searching (Cassell, Jackson, \& Cheuvront, 1998; Suggs, 2006). For example, a patient may seek confirmation or disconfirmation of a doctor's diagnosis in order to evaluate its accuracy (Northouse \& Northouse, 1998). Health information acquired online provides information for people in need of second medical opinions (Fox \& Rainei, 2002; Taylor \& Leitman, 2004). This illustrates two new concepts in healthcare-firstly, health information is no longer dominated entirely by health professionals--and secondly, people now tend to take greater responsibility for their health (Eysenbach, 2000; Hardey, 1999， 2001; Lowrey \& Anderson, 2006).

Reflecting this trend, the use of online health information (i.e., e-health) has been defined as "the use of emerging information and communication technology, especially the Internet, to improve or enable health and health care" (Eng, 2001, p. 2). It has also been defined as "the use of information and communication technologies in the communication of health information and advice both to patients/public and between members of the public" (Henwood \& Balka, 2004, p. v). Thus, e-health can be considered an online behavior, in which people exploit the Internet to teach themselves about their own health and manage their own healthcare (Wilkins, 1999). The definition of e-health thus excludes Internet-based diagnosis and treatment by health professionals.

Although researchers have become interested in investigations of e-health information use (Haviland, Pincus,

*Address correspondence to this author at the School of Communication, 52 Hyochangwon-gil, Yongsan-gu, Sookmyung Women's University, Seoul, Korea 140-742 , Korea; Tel: (82) 2-2077-7376; Fax: (82) 2-710-9731;

E-mail: jwshim@sookmyung.ac.kr
\& Dial, 2003; Henwood \& Balka, 2004; Morahan-Martin, 2004), less attention has been paid to the following issueswhat factors drive people to use e-health information?; how do people behave online to obtain this information?; and finally, how does e-health information use impact one's health behavior? Recently, research findings have shown that the manner in which people perceive their health condition may motivate them to go online in pursuit of health information (Houston \& Allison, 2002; Miilunpalo, Vuori, Oja, Pasanen, \& Urponen, 1997). In addition, some studies have indicated that people can be segmented in accordance with their use of the Internet for health-associated purposes (Fox \& Rainei, 2002; Nettleton, Burrows, O'Malley, \& Watt, 2004). With these studies in mind, the principal objective of this study was to determine the relationship between e-health information use and changes in health behavior, with an emphasis placed on the role of self-perceived health status and type of e-health use. In this study, we began with the expectation that perceived health status and types of e-health use would be relevant to the amount of e-health use, and that individuals' health behavior might be affected by health information acquired online.

\section{PERCEIVED HEALTH STATUS AND ONLINE HEALTH INFORMATION USE}

Perceived health status is defined as "the subjective health assessment that reflects a person's integrated perception of health, including its biological, psychological, and social dimensions, that is inaccessible to any external observer" (Miilunpalo et al. 1997, p. 517). Perceived health status is a personal perception, and represents "the way that individuals feel about their health status" (Fayers \& Sprangers, 2002, p. 187).

Several studies have evaluated the effects of perceived health status on the use of e-health information. However, the findings in this regard have been somewhat inconsistent; some argue that a substantial relationship exists, whereas others do not. Houston and Allison (2002) determined that people with low perceived health status are more likely to 
utilize e-health information than those with high perceived health status. Similarly, individuals who reported worse health status were more likely to search for health information, e-mail family or friends, and e-mail others than were those with higher self-perceived health status (Baker, Wagner, Singer, \& Bundorf, 2003). However, Bowen et al. (2003) determined that women who describe themselves as being generally healthy utilize e-health information more frequently than those who describe themselves as generally unhealthy. In addition, women who describe themselves as mentally problematic use e-health information less frequently than those who describe themselves as mentally sound.

Although there is currently no consensus regarding the effects of perceived health status, this study proposes that one's perceived health status is one factor that affects the amount of e-health information use. On one hand, this argument is predicated on the idea that perceived health status is reflective to some degree of an individual's psychological state. For example, a low perception of health condition has been associated with psychological distress, such as dysphoria, nervousness, and negative affect (Tessler \& Mechanic, 1978). Accordingly, it appears probable that those with poor self-assessed health are in a distressed state, and feel a need for information to determine the cause of their poor condition, as well as possible treatments. The other reason involves the possibility that health information can reduce uncertainty regarding one's health issues. Although the number of diseases reported for which no treatment is sought are increasing, people appear to have become more concerned about their health than at any other time, and many individuals express feeling highly uncertain with regard to their health. The Internet is the primary information source for many people in terms of unfamiliar health issues. While searching for health information online, people usually attempt to find symptoms similar to their own, and then search for possible causes and consequences, as well as the opinions of others.

The current lack of research renders it difficult to predict the relationship between perceived health status and e-health information use. However, in this study, we expected that the variance of perceived health status might be predictive with regard to the frequency of online health information use, and this variable is also more likely to be associated with ehealth information searching behavior. Considering that individuals in poor health conditions are more in need of information than are those in better health, it is reasonable to infer that people with generally bad health are more likely to consult Internet resources for medical information. As a result, they will tend to utilize the Internet more frequently than those in good health. Based on this rationale, we formulated the following hypothesis.

Hypothesis 1: Those who perceive their health as being poor will be more likely to utilize e-health information than those who perceive their health as being generally good.

\section{SEGMENTATIONS OF E-HEALTH INFORMATION USE}

Some attempts have been made to identify the structure of e-health use (Nettleton et al., 2004; Neuhauser \& Kreps, 2003; Taylor \& Leiman, 2001). Researchers have repeatedly attempted to understand multiple dimensions of e-health use, in accordance with certain criteria.

Via in-depth interviews with families with children who suffer from chronic illnesses, Nettleton et al. (2004) observed that people vary with regard to their levels of comfort with the Internet, as well as in their forms of reflexive engagement. On the basis of the two criteria, they identified six types of e-health information use--reluctant searchers and gatherers, purposeful searchers and gatherers, and surfing searchers and gatherers.

Taylor and Leiman (2001) determined that patients' ehealth information use patterns were associated with their ehealth use types. For example, the accepting type of patients are entirely dependent upon health professionals, and tend never to utilize e-health information. By way of contrast, the in control type of patients are the most likely to depend on ehealth information. For the informed type of patients, the principal source of health information is the clinician, but this type of patient also tends to view e-health as an alternative medical source, which supplements or complements the information provided by doctors. Involved type patients utilize the Internet in order to have health discussions with their clinicians.

Fox and Rainie (2002), using 500 users of e-health information, identified three types of e-health information use: vigilant, concerned, and unconcerned. Vigilant type individuals are regarded as the most disciplined users, as they frequently check the sources, updated information, and privacy policies of health sites. People of the concerned type utilize the Internet for information on how to deal with their current medical problems. Unconcerned type individuals are generally healthy, and do not tend to perceive e-health information as being useful.

Research into the typology of e-health information use is important because it shows that people behave differently online when they search for health information, and these differences influence the degree of reliance on e-health information usage. Furthermore, typology research has shown that the relationship between people's perceived health status and the overall quantity of e-health use may depend heavily on e-health types.

Although previous typologies have contributed greatly to the area of e-health communication research, they are also somewhat limited. For example, these typologies are useful for understanding medical patients' e-health information use, but they are less applicable to non-patient populations (e.g., Taylor \& Leiman, 2001; Fox \& Rainie, 2002). The six ehealth types devised by Nettleton et al. (2004) have not yet been developed sufficiently for empirical testing. Thus, it appears necessary to develop a typology that is both testable and applicable to the general population.

\section{PERCEIVED HEALTH STATUS, TYPES OF E- HEALTH USE, AND E-HEALTH INFORMATION USE}

The current study proposes a new typology of e-health information use, which is focused on the manner in which people behave online to obtain e-health information. This typology is referred to as behavior-based e-health segmentation: purposeful, wary, and listserv. These types delineate three dimensions to health-related Internet use. 
First, purposeful e-health use refers to the online search behavior by which people attempt to acquire e-health information to serve their specific purposes. Examples of purposeful use include the use of the Internet to find information regarding particular illnesses or conditions; find information regarding mental health issues such as depression or anxiety; and find information that might be useful to prevent those illnesses. As the examples show, it is likely that a poor self-perception of health condition is associated with purposeful e-health use. That is to say, those who believe that their health is generally poor will utilize the Internet until they find information that corroborates their personal beliefs about their condition. As a result, they will be more likely to spend time finding e-health information on the Internet that fits their perceptions. Thus, in this study, we propose two additional hypotheses.

Hypothesis 2: Those who perceive that their health is poor will be more likely to be associated with purposeful ehealth use than those who perceive their health as generally good.

Hypothesis 3: People who evidence high degrees of purposeful use are more likely to spend time searching for ehealth information than those evidencing low levels of purposeful use.

Wary e-health use refers to a type of online search behavior in which individuals carefully assess the quality of e-health information by considering the credibility of the websites utilized. According to the results of recent studies, people do not, in general, pay attention to elements of credibility (Fox, 2006). However, the credibility of websites is far more important than the quantity of information available on the Internet for this type of people. The typical behaviors associated with wary e-health use include researching the credibility of health websites by reading their privacy policies, determining the authorship or authority of the sites, and evaluating the recency of the information. These, incidentally, are the most common criteria for evaluations of the credibility of websites (Kapoun, 1998). Fox and Rainie (2002) referred to such individuals as "vigilant seekers". It is expected that those who perceive their health to be poor are less likely to be wary-type individuals, because their primary interest is to find immediate and relevant information, rather than to first read the credibility elements. Those generally concerned with credibility will be conservative in the manner in which they process health information, with regard to their acquisition, evaluation, and behavior (Benigeri \& Pluye, 2003; Hirji, 2004; Nettleton et al., 2004). Thus, the more wary an individual is in his or her e-health use, the more likely that individual is to spend time evaluating the credibility of health information rather than spending time actually reading the health information. Once such an individual feels that a website is not credible, that individual will tend to disregard all health information obtained from that site. People who evidence wariness in their e-health use patterns will continue to search online until they confirm the trustworthiness of the available health information. In this regard, an expectation of this study was that wary e-health use should be positively related with the amount of e-health information. In that respect, we propose two additional hypotheses.
Hypothesis 4: Those who perceive their health as being poor will be less likely to be associated with wary e-health use than those who perceive their health to be generally good.

Hypothesis 5: People who evidence highly wary use are more likely to spend time on e-health information searching than those who evidence less wary use.

Finally, listserv e-health use refers to a type of online search behavior in which individuals simply receive information from other online users or health websites by joining them as members, but are not actively involved in the process of e-health information searching and processing. The principal objectives of listserv e-health use are to take advantage of online health information by joining mailing lists or by signing up for electronic newsletters that e-mail them the latest health news or medical updates. For example, such users obtain the majority of their Internet health information simply by checking their e-mail accounts, and reading the delivered content. Thus, it can be asserted that listserv-style e-health users believe that they can obtain adequate health information without becoming active participants. Given that those who perceive their health to be poor are generally in need of more health-related information, it is expected that they will be more likely to be the listserv e-health user type than those who perceive their health to be generally good. Although the listserv e-health type is not necessarily associated with active involvement in the interactive health information flow, listserv-style use is probably associated with the amount of e-health use, in that it takes time to read delivered mails and to attempt to find other mailing sites. Here, we propose two additional hypotheses.

Hypothesis 6: Those who perceive their health as poor will be more likely to be associated with listserv-style ehealth use than those who perceive their health as generally good.

Hypothesis 7: People evidencing a high level of listserv use are more likely to spend time in e-health information searches than those evidencing low levels of listserv use.

\section{ONLINE HEALTH INFORMATION USE AND HEALTH BEHAVIOR CHANGE}

Studies show that web-based activities such as surfing and searching are above a certain cognitive threshold, thereby indicating that they are fundamentally a motivated online behavior (Chen, Houston, Sewell, \& Schatz, 1998; Dutta-Bergman, 2003; Wellman, Haase, Witte, \& Hampton, 2001). Dutta-Bergman (2003) demonstrated that, unlike his initial expectation that online surfing is less motivated than online searching, both surfing and searching appear to require cognitive efforts above the information processing threshold. Chen et al. (1998) argued that, based on motivational aspects, online activity is both goal-directed and experiential. Wellman et al. (2001) argued that people who have been online for a longer period tend to engage in more types of Internet activities. Therefore, it is reasonable to assume that those who frequently go online to seek health information will tend to change their health-related behavior on the basis of information acquired from the Internet more frequently than those who do not frequently go online. Here, we propose Hypothesis 8 . 
Hypothesis 8: The more frequently people utilize e-health information, the more changes they will make in their health behaviors.

Fig. (1) summarizes the expected relationship between variables. As will become clear later, the arrows represent the hypotheses presented above.

It has been determined that certain demographic variables are correlated with e-health information use. For example, women are more likely to go online to obtain e-health information than are men (Brodie et al., 2000; Fox, 2006; Fox \& Rainie, 2002). Those who have higher education are more likely to use e-health information than those with lower education. For example, college graduates were more likely to use the Internet to obtain health information than those with high school educations (Brodie et al., 2000; Fox \& Rainie, 2002). Age has also been associated with e-health information seeking, in that people between the ages of 50 and 64 were most likely to search for medical information in comparison with other age groups (Fox \& Rainie, 2002). In addition, income has been associated with e-health information use, in that people with higher incomes $(\$ 50,000$ or more a year) are more likely to use the Internet to obtain health information than are those with lower incomes (less than $\$ 30,000$ a year) (Brodie et al., 2000). Thus, this study controls for the four demographic variables in the following regression analyses.

\section{METHODOLOGY}

Data used in this study was obtained from the 2001 Health Callback Data Set of PEW Internet \& American Life Project Online Data Sources. This Callback Data was based on telephone interviews conducted between June 19 and August 6, 2001 using a sample of 500 Internet users who in past surveys had identified themselves as seekers of Internet health information. The PEW Internet \& American Life Project Online Data Sources offers a publicly available source of national-level data for American people's Internet use in a variety of aspects. ${ }^{1}$ The response rate for the callback portion of the survey was $54 \%$. Thirty nine percent of the participants were males $(n=193)$ and $61 \%$ were females $(n=307)$. The average age of the participants was $45(S D=14)$. In terms of racial background, $89 \%$ of the participants identified themselves as white and 5\% identified as black or African-American, followed by Asians or Pacific Islanders $(2 \%)$, mixed race $(1 \%)$, and others $(3 \%)$.

\section{Measures \\ Demographics}

Demographics employed as control variables included age, gender, education, and income. Age was an open-ended question. Education was measured as follows: (1) None, or grade 1-8, (2) High school incomplete (grade 9-11), (3) High school graduate, (4) Business, technical, or vocational school after high school, (5) Some college, no 4-year degree, (6) College graduate, and (7) Post-graduate training/professional school after college $(M=5.3, S D=1.4)$. Household income was classified as follows: (1) Less than $\$ 10,000$, (2) $\$ 10,000$ to under $\$ 20,000$, (3) $\$ 20,000$ to under $\$ 30,000$, (4) $\$ 30,000$

${ }^{1}$ Details on the use of data can be found at http://www.pewinternet.org/data.asp. to under $\$ 40,000$, (5) $\$ 40,000$ to under $\$ 50,000$, (6) $\$ 50,000$ to under $\$ 75,000$, (7) $\$ 75,000$ to under $\$ 100,000$, and (8) $\$ 100,000$ or more $(M=5.4, S D=1.9)$.

\section{Perceived Health Status}

In an effort to assess an individual's self-perceived health status, a single question was used to ask people to rate their overall health on a scale from poor to excellent. This is one of the most frequently utilized measures of perceived health status (Fayers \& Sprangers, 2002). Respondents were asked to rate their own health. Responses were (1) poor, (2) only fair, (3) good, and (4) excellent. The mean score of perceived health status was $3.14(S D=.69)$.

\section{E-Health Information Use}

The amount of e-health information use was measured by a single, general health information use item. Respondents were asked how often they utilized the Internet to look for advice or information regarding health or health care. Responses were (1) less often, (2) every few months, (3) several times a month, (4) several times a week, and (5) every day. The mean score of the amount of e-health information use was $2.48(S D=1.02)$.

\section{Types of Online Health Information Use}

Factor analyses were conducted in order to identify etypes using 10 online items related to seeking online health information via Principal Component Analysis using the Varimax rotation option (see Appendix for full list of items). The 10 items were broken into 3 components: purposeful use, wary use, and listserv use. The explained variance was $51.7 \%$. This analysis revealed a three-factor solution with no significant cross readings.

\section{Purposeful E-Health Use}

Purposeful e-health use was defined as the online search behavior in which people utilize e-health information to seek e-health information that fits their specific purposes. It is comprised of 4 questions, each item being answered no or yes. A sample item is "Have you ever used the Internet to look for information about a mental health issue like depression or anxiety?". The reliability among the six items was found to be modest $(K R 20=.51)$. Thus, purposeful use was calculated by summing the 4 items $(M=5.84, S D=$ 1.24). The scores ranged from 4 to 8 .

\section{Wary E-Health Use}

Wary e-health use was defined as online search behavior in which people carefully assess the elements of credibility of health websites. It is comprised of 3 questions, each item being rated with a 5-point scale ranging from "never" to "always." A sample item is "how often do you look into the privacy policies of the health web sites you visit?". The reliability among the three items was found to be acceptable, $\alpha=.67$. Wary use value was generated by summing the 3 items $(M=9.29, S D=2.95)$. The scores ranged from 3 to 15 .

\section{Listserv E-Health Use}

Listserv e-health use was defined as an online search behavior pattern in which people simply receive health information via emails, without actually surfing health websites. It is comprised of 3 questions, each item being 
$\mathrm{H} 1$

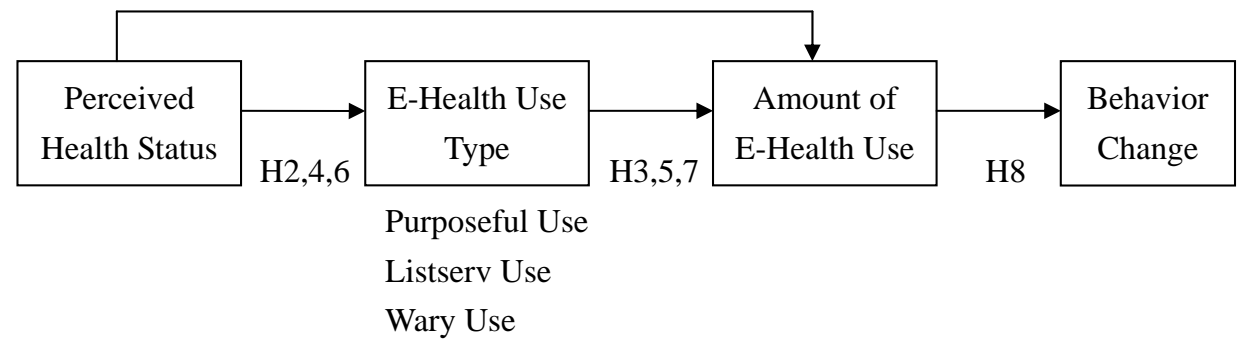

Fig. (1). Expected relationship between perceived health status, types of e-health information use, amount of e-health information use, and behavior change.

answered yes or no. A sample item is "Have you ever signed up for an electronic newsletter that emails the latest health news or medical updates?". The reliability among the 3 items was found to be modest $(K R 20=.57)$. Listserv e-health use was generated by summing the three items $(M=3.35, S D=$ .71). The scores ranged from 3 to 6 .

\section{Behavior Change}

Behavior change was defined as an individual's experience of changes in health behavior. It is comprised of 6 questions, each item being answered yes or no. A sample item is "Did the information you found online affect a decision about hot to treat an illness or condition?" (see Appendix for full list of items). The reliability among the six items was found to be modest $(K R 20=.65)$. Thus, behavior change was generated by summing the 6 items $(M=7.85$, $S D=1.66)$. The scores ranged from 6 to 12 .

\section{RESULTS}

Zero-order correlation analyses showed that the variables were weakly correlated with each other (see Table 1). Perceived health status was negatively related with the use of health information $(r=-.16, p<.01)$, thereby suggesting that people with low perceived health status are more likely to seek health information on the Internet. In addition, people with low perceived health status tended to be more purposeful in their e-health use $(r=-.12, p<.01)$ and listserv e-health use $(r=-.11, p<.05)$, and to change their health behaviors $(r=-.11, p<.05)$. The three types of e-health information use were weakly correlated: purposeful e-health use and listserv e-health use $(r=.24, p<.01)$, purposeful ehealth use and wary e-health use $(r=.23, p<.01)$, and wary e-health use and listserv e-health use $(r=.12, p<.05)$. They were positively associated with the amount of e-health information use: wary e-health use $(r=.13, p<.01)$, purposeful e-health use $(r=.22, p<.01)$, and listserv e-health use $(r=.23, p<.01)$. In addition, they were positively correlated with behavior change: wary e-health use $(r=.21, p$ $<.01)$, purposeful e-health use $(r=.28, p<.01)$, and listserv e-health use $(r=.14, p<.01)$. Finally, the amount of e-health information use was significantly correlated with changes in behavior $(r=.12, p<.05)$

Hierarchical regression analyses were conducted to test the proposed hypotheses. Hypothesis 1 concerned the effects of perceived health status on the amount of e-health use. After controlling for demographic variables, perceived health status revealed a statistically significant influence on the amount of e-health use, $\beta=-.15, p<.01$, thereby indicating that those who described their health as poor were more likely to go online for the purpose of finding health information than those who described their health as generally good (see column 4 in Table 2). Hypotheses 2, 4 , and 6 involved the relationships between perceived health status and each type of e-health information use. Controlling for demographic variables, three hierarchical regression analyses were run. Those with poor perceived health status were more likely than those with good perceived heath status to be associated with purposeful e-health use, $\beta=-.14, p<$ .01 , and listserv e-health use, $\beta=-.11, p<.05$. Hypotheses 2 and 6 were supported. However, no significant relationship was found to exist between perceived health status and wary e-health use (see columns $1 \sim 3$ in Table 2).

Hypotheses 3, 5, and 7 involved the effects of e-health use types on the amount of e-health information use. Hierarchical regression analysis showed that purposeful ehealth use $(\beta=.16, p<.01)$ and listserv e-health use $(\beta=$ $.16, p<.01)$ were positively correlated with the amount of ehealth information use. Hypotheses 3 and 7 were supported. However, no significant relationship was found to exist between wary e-health use and the amount of e-health information use (see column 5 in Table 2).

Hypothesis 8 involved the effects of e-health information use on behavior changes. Controlling for demographic variables, perceived health status, and the three types of health information user, the amount of e-health information use was found to have no effect on behavior changes (see column 6 in Table 2). Hypothesis 8 was not supported. Although it was not expected, the levels of purposeful ehealth use and wary e-health use were related positively to changes in behavior: $\beta=.26, p<.001$ and $\beta=.18, p<.01$, respectively.

\section{DISCUSSION}

The principal objective of this study was to integrate the relationships existing among perceived health status, types of e-health use, the amount of e-health information use, and changes in behavior. Perceived health status was defined as the general self-rated health condition. With an emphasis on online behavior, this study identified three types of e-health information users: purposeful, wary, and listserv users. In brief, people in the purposeful e-health use category are those who are interested in finding information that fits their symptoms, and tend to pay less attention to the credibility of such informational websites. Small symptoms compel them 
Table 1. Zero-Order Correlations Between Variables

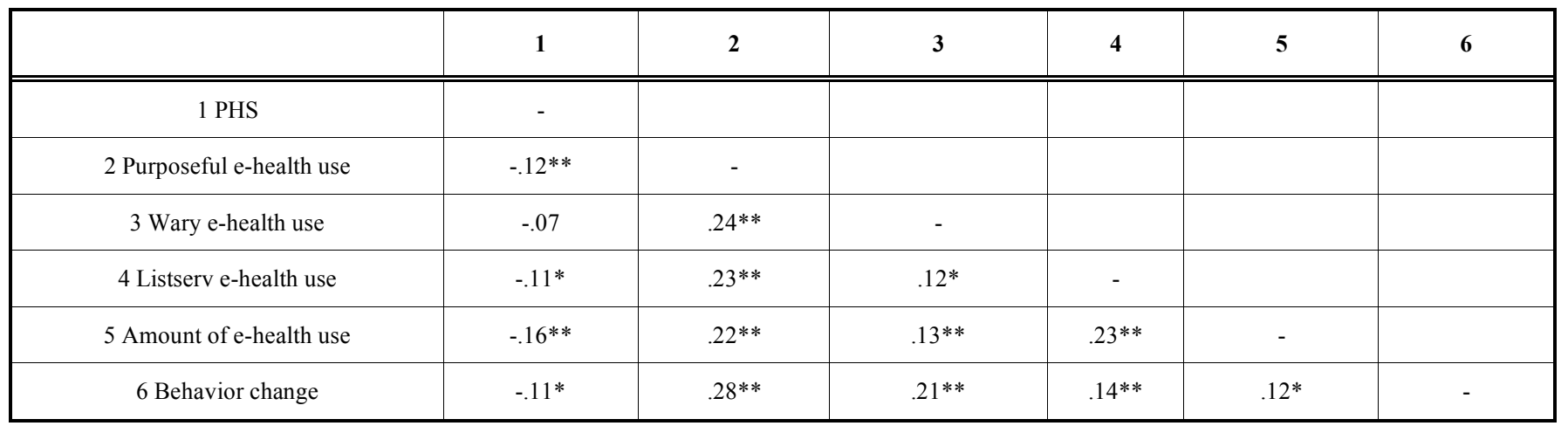

Note. PHS refers to Perceived Health Status.

$* p<0.05, * * p<0.01$.

Table 2. Hierarchical Regressions on Types of E-Health Information Use, Amount of E-Health Information Use, and Behavior Change

\begin{tabular}{|c|c|c|c|c|c|c|}
\hline & Purposeful e- & Wary & Listserv & \multicolumn{2}{|c|}{ Amount of E-Health Use } & \multirow{2}{*}{$\begin{array}{c}\begin{array}{c}\text { Behavior } \\
\text { Change }\end{array} \\
6\end{array}$} \\
\hline Column & 1 & 2 & 3 & 4 & 5 & \\
\hline $\operatorname{Sex}(f=0)$ & .03 & -.04 & -.03 & -.01 & -.03 & .02 \\
\hline Age & -.06 & -.05 & -.05 & .0 & .02 & .00 \\
\hline Income & .10 & -.05 & .04 & -.01 & -.04 & -.09 \\
\hline PHS & $-.14 * *$ & -.06 & $-.11 *$ & $-.17 * * *$ & $-.15^{* *}$ & .01 \\
\hline Purposeful use & & & & & $.16^{* *}$ & $.26^{* * *}$ \\
\hline Wary use & & & & & .09 & $.18 * *$ \\
\hline
\end{tabular}

Note. Coefficients are final standardized beta coefficients.

$* p<.05, * * p<0.01, * * * p<0.001$.

to search the Internet to know what others have to say on certain health subjects. People in the wary e-health use category are those who are concerned about the accuracy of information, in that inaccurate information might exacerbate certain health problems. People in the listserv e-health use category are those who receive information simply by mailing subscriptions, without actively involving themselves in the information flow.

Findings indicated that perceived health status was significantly correlated with purposeful e-health information use, listserv e-health information use, and the amount of ehealth information use. This finding shows that those who feel that they have problematic health condition are more likely than those who feel that they are in good health to be either those who use e-health information for specific purposes or those who simply subscribe to e-health mailing lists. One's self-perceived health status was not found to be related to wary e-health information use. Unlike Bowen et al. (2003), those with low self-perceived health status were more likely to spend time searching for health information than those with higher self-perceived health status. In support of the results of Settersten and Lauver (2004), this research showed no significant relationship existing between perceived health status and behavior changes.

With regard to the role of the three types of e-health information use, purposeful use and listserv use were positively related to the amount of e-health information use. No significant relationship was found to exist between wary e-health use and the amount of e-health information use. Purposeful e-health use and wary e-health use were positively related with changes in behavior. After controlling for demographic variables, self-perceived health status, and e-health information use types, the amount of e-health use was not found to be predictive of changes in behavior. It is worthy of note that purposeful e-health use mediates the effects of the amount of e-health information use on changes in behavior. Thus, it can be concluded that behavior change as a result of e-health information use is most likely in people with low perceived health status who evidence purposeful e-health use. People in the wary use category tend 
to change their health behavior patterns once the e-health information they find has been shown to be credible and accurate, based upon certain criteria including information recency, authorship, and clear policy, regardless of their perceived health status and the amount of available e-health information.

In summary, one's perceived health status motivates people to surf/search the Internet for health purposes, but the typology of e-health information use (particularly purposeful e-health use) moderates the relationship between the amount of e-health information use and changes in behavior. Accordingly, perceived health status makes people feel that poor health can be avoided by using the Internet. By maintaining positive expectations or by searching for online health information, one may avoid poor health (Brashers, Goldsmith, \& Hsieh, 2002).

E-health information use may constitute a strategy for individuals to avoid the current uncertainty regarding selfhealth assessments. It appears possible that Internet usage can reduce such uncertainty, due to certain characteristics of the Internet, including interactivity, flexibility, and immediate feedback (Bowen et al., 2003; Cassell et al., 1998). Given that many health problems (AIDS, safe sex, cancer, etc) are both urgent and costly, it is difficult to generate profitable effects solely as the result of communication and health campaigns (Slater, 1996). Ehealth use typology, therefore, is a way to tailor users and to obtain more helpful information. Tailored messages tend to be more effective than generic messages in communication (Eng, 2002; Neuhauser \& Kreps, 2003). It would also be useful to determine which types of users obtain poor or inaccurate health information.

As many scholars have reported, e-health information can make worsen the conditions of so-called self-empowered people, however. Some findings warrant such concerns. Neuhauser and Kreps (2003) determined that the accuracy of certain credible health websites was only fair with regard to general health issues. The general public lacks the ability to accurately assess the quality of e-health information (Shepperd, Charnock, \& Gann, 1999). In addition, people tend not to consider the accuracy of such sites, instead attempting to find information that fits their needs (Fox, 2006; Pautler et al., 2001). In this regard, Benigeri and Pluey (2003) argue that users of e-health information might experience health problems when they incorrectly interpret information or try inappropriate treatments. Similarly, Pereira and Bruera (1998) previously argued that online support groups in which sensational personal anecdotes and biased personal views abound could cause serious health problems.

Accordingly, Morahan-Martin (2004) suggests an active role of health professionals in the age of self-empowered people: health professionals should then recommend credible and useful sites; promote more effective search and evaluation techniques; and develop and promote uniform standards for health and mental health sites. Health professionals should be made aware of the diverse uses of ehealth information of the population by examining "Increasing integration into practice to enhance time-saving aspects and improve patient education might lead to more sustained use of this promising communication tool."
(Houston, Sands, Nash, \& Ford, 2003, p. 516). Without being aware of such aspects, doctors' usage of online technology has no effect, because people tend to believe that they have no need of health professionals to obtain health information on the Internet (Lowrey \& Anderson, 2006).

Utilizing an existing data set offers several advantages, but also limits a study in several ways. First, rather than developing measures of variables, in this study we opted to measure those variables on the basis of available items in the dataset. A more appropriate and sensitive measure of variables might better capture this impact. In addition, the majority of the items were dichotomous. In future research, items need to be developed using ordinal or ratio-level data. Secondly, this study is an exploratory analysis, which requires follow-up with more advanced methods, utilizing structural equation models to develop a more complete and accurate understanding of the relevant relationships. Finally, this study utilized a cross-sectional design, and thus no causal relationships can be inferred.

\section{APPENDIX}

\section{Purposeful Use}

a Have you ever used the Internet to look for information about a mental health issue like depression or anxiety?

b Have you ever used the Internet to look for information about alternative or experimental treatments or medicines?

c Have you ever used the Internet to look for information about a sensitive health topic that is difficult to talk about?

d Have you ever used the Internet to look for information about prescription drugs?

\section{Wary Use}

a How often do you look into the privacy policies of the health web sites you visit?

b How often do you look to see who provides the information on the health websites you visit?

c How often do you look to see when the information on a health website was last updated?

\section{Listserv Use}

a Have you ever set up a personal profile at a favorite health web site, or customized a health web site so you receive only the information you're most interested in?

b Have you ever participated in an online support group or email list for people concerned about a particular health or medical issue?

c Have you ever signed up for an electronic newsletter that emails the latest health news or medical updates?

\section{Behavior Change}

In which of the following ways, if any, did the information you found online affect your own health care routine or the way you care for someone else? Did the information you found online... 
a Affect a decision about how to treat an illness or condition?

b Change your overall approach to maintaining your health or the health of someone you help take care of?

c Change the way you cope with a chronic condition or manage pain?

d Affect a decision about whether to see a doctor?

e Lead you to ask a doctor new questions, or to get a second opinion from another doctor?

f Change the way you think about diet, exercise, or stress management?

\section{REFERENCES}

Baker, L., Wagner, T.H., Singer, S., \& Bundorf, M.K. (2003). Use of the Internet and email for health care information. Journal of the American Medical Association 289, 2400-06.

Benigeri, M., \& Pluye, P. (2003). Shortcomings of health information on the Internet. Health Promotion International 18, 381-6.

Bowen, D.J., Meischke, H., Bush, N., Wooldridge, J.A., Robbins, R., Ludwig, A., Escamilla, G. (2003). Predictors of women's Internet access and Internet health seeking. Health Care for Women International 24, 940-51.

Brashers, D., Goldsmith, D., \& Hsieh, E. (2002). Information seeking and avoiding in health contexts. Human Communication Research 28, 258-71

Brodie, M., Flournoy, R.E., Altman, D.E., Blendon, R.J., Benson, J.M., \& Rosenbaum, M.D. (2000). Health information, the Internet, and the digital divide. Health Affairs 19, 255-65.

Cassell, M., Jackson, C., \& Cheuvront, B. (1998). Health communication on the Internet: An effective channel for health behavior change? Journal of Health Communication 3, 71-9.

Chen, H., Houston, A., Sewell, R.R., \& Schatz, B.R. (1998). Internet browsing and searching: User evaluations of category map and concept space techniques. Journal of the American Society for Information Science 49, 582-603.

Dutta-Bergman, M. (2003). Health communication on the Web: The roles of Web use motivation and information completeness. Communication Monographs 70, 264-74.

Eng, T.R. (2002). eHealth research and evaluation: Challenges and opportunities. Journal of Health Communication 7, 267-72.

Eng, T.R. (2001). The eHealth landscape: A terrain map of emerging information and communication technologies in health and health care. Princeton, NJ: The Robert Wood Johnson Foundation.

Eysenbach, G. (2000). Consumer health informatics. British Medical Journal 320, 1713-6.

Fayers, P.M., \& Sprangers, M. A. (2002). Understanding self-rated health. Lancet 359, 187-8.

Fox, S. (2006). Online heath search 2006. Retrieved August 5, 2007 from the World Wide Web: http://www.pewinternet.org/pdfs/PIP_Online Health_2006.pdf

Fox, S., \& Rainie, L. (2002). Vital decisions: How Internet users decide what information to trust when they or their loved ones are sick, from Washington DC: Pew Internet \& American Life Project. Retrieved August 10, 2007, from the World Wide Web: http://www.pewinternet.org/reports/toc. asp?Report $=59$

Hardey, M. (1999). Doctor in the house: The Internet as a source of lay health knowledge and the challenge of expertise. Sociology of Health and Illness 21, 820-35.

Hardey, M. (2001). 'E-health': The Internet and the transformation of patients into consumers and producers of health knowledge. Information, Communication \& Society 4, 388-405.
Haviland, M.G., Pincus, H.A., \& Dial, T.H. (2003). Type of illness and use of the Internet for health information. Psychiatric Services 54, 1198.

Henwood, F., \& Balka, E. (2004). Editorial comment. Information, Communication \& Society 7(4), v-iv.

Hirji, F. (2004). Freedom or folly? Canadians and the consumption of online health information. Information, Communication \& Society 7, 44565.

Houston, K.T., \& Allison, J.J. (2002). Users of Internet health information: Differences by health status. Journal of Medical Internet Research 4(2), e7.

Houston, T.K., Sands, D.Z., Nash, B.R., \& Ford, D.E. (2003). Experiences of physicians who frequently use e-mail with patients. Health Communication 15, 515-25.

Kapoun, J. (1998). Teaching undergrads WEB evaluation: A guide for library instruction. College and Research Libraries News 59(7), 522-3.

Lowrey, W., \& Anderson, W.B. (2006). The impact of Internet use on the public perception of physicians: A perspective from the sociology of professions literature. Health Communication 19, 125-31.

Miilunpalo, S., Vuori, I., Oja, P., Pasanen, M., \& Urponen, H. (1997). Selfrated health status as a health measure: The predictive value of selfrated health status on the use of physician services and on mortality in the working-age population. Journal of Clinical Epidemiology $50,517-28$.

Morahan-Martin, J. M. (2004). How Internet users find, evaluate, and use online health information: A cross-cultural review. CyberPsychology \& Behavior 7, 497-510.

Nettleton, S., Burrows, R., O'Malley, L., \& Watt, I. (2004). Health E-Types? Information, Communication \& Society 7, 531-53.

Neuhauser, L., \& Kreps, G.L. (2003). Rethinking communication in the Ehealth era. Journal of Health Psychology 8, 7-23.

Northouse, L.L., \& Northouse, P.G. (1998). Health communication: Strategies for health professionals. Stamford, CT: Appleton \& Lange.

Pautler, S.E., Tan, J.K., Dugas, G.R., Pus, N., Ferri, M., \& Hardie, W.R. (2001). Use of the Internet for self-education by patients with prostate cancer. Urology 57, 230-3.

Pereira, J., \& Bruera, E. (1998). The Internet as a resource for palliative care and hospice: A review and proposals. Journal of Pain and Symptom Management 16, 59-68.

Settersten, L., \& Lauver, D.R. (2004). Critical thinking, perceived health status, and participation in health behaviors. Nursing Research 53, 11-8.

Shepperd, S., Charnock, D., \& Gann, B. (1999). Helping patients' access high quality health information. British Medical Journal 319, 7646.

Slater, M. (1996). Theory and method in health audience segmentation. Journal of Health Communication 1, 267-84.

Suggs, L.S. (2006). A 10-year retrospective of research in new technologies for health communication. Journal of Health Communication 11, 61-74.

Taylor, H., \& Leitman, R. (2001). The increasing impact of eHealth on consumer behavior. Health Care News 1(21), 1-9.

Taylor, H., \& Leitman, R. (2004). No significant change in the number of "Cyberchondriacs" - Those who go online for health care information. Health Care News 4(7), 1-4.

Tessler, R., \& Mechanic, D. (1978). Psychological distress and perceived health status. Journal of Health \& Social Behavior 19, 254-62.

Wellman, B., Haase, A.Q., Witte, J., \& Hampton, K. (2001). Does the Internet increase, decrease, or supplement social capital? Social networks, participation, and community commitment. American Behavioral Scientist 45, 437-56.

Wilkins, A. (1999). Expanding Internet access for health care consumers. Health Care Management Review 24(3), 30-41. 